\title{
Review
}

\section{Arterial stiffness: a brief review}

Najeeb A SHIRWANY, Ming-hui ZOU

Division of Endocrinology and Diabetes, Department of Medicine, University of Oklahoma Health Science Center, Oklahoma City, OK 73104, USA

\begin{abstract}
Physical stiffening of the large arteries is the central paradigm of vascular aging. Indeed, stiffening in the larger central arterial system, such as the aortic tree, significantly contributes to cardiovascular diseases in older individuals and is positively associated with systolic hypertension, coronary artery disease, stroke, heart failure and atrial fibrillation, which are the leading causes of mortality in the developed countries and also in the developing world as estimated in 2010 by World Health Organizations. Thus, better, less invasive and more accurate measures of arterial stiffness have been developed, which prove useful as diagnostic indices, pathophysiological markers and predictive indicators of disease. This article presents a review of the structural determinants of vascular stiffening, its pathophysiologic determinants and its implications for vascular research and medicine. A critical discussion of new techniques for assessing vascular stiffness is also presented.
\end{abstract}

Keywords: aortic stiffness; cardiovascular diseases; pathophysiology; clinical relevance

Acta Pharmacologica Sinica (2010) 31: 1267-1276; doi: 10.1038/aps.2010.123; published online 30 Aug 2010

\section{Introduction}

While generalized stiffening of the vasculature as a hallmark of normal aging has been recognized even in ancient medical texts, systematic scientific evaluation of arterial stiffening and particularly the type that affects the central arterial axis (ie the aortic system and its central branches) has only matured as a clinical and research discipline in recent decades. Stiffening in the larger central arterial system, such as the aortic tree, significantly contributes to cardiovascular diseases in older individuals and is positively associated with systolic hypertension ${ }^{[1]}$, coronary artery disease $\mathrm{e}^{[2]}$, stroke $\mathrm{e}^{[2]}$, heart failure ${ }^{[3]}$ and atrial fibrillation $^{[4]}$. Central arterial stiffening is now fully recognized as an important consequence of aging that has been shown to provoke deleterious vascular phenotypes in diseases such as diabetes, atherosclerosis and renal disease among others ${ }^{[5]}$. Therefore predictably, there is a consistent increase in the incidence and prevalence of the surrogate markers of vascular stiffening in these conditions and these are typically pulse pressure and isolated systolic hypertension ${ }^{[6-9]}$.

Arteries deliver blood at high pressure to peripheral vascular beds. The arterial system can be functionally (as well as structurally) divided into two sub-systems: (a) the large elastic arteries (eg the aorta, the carotid vessels, the iliac arter-

\footnotetext{
* To whom correspondence should be addressed.

E-mail ming-hui-zou@ouhsc.edu

Received 2010-04-16 Accepted 2010-06-12
}

ies), which store blood ejected from the heart during systole, and expel it to the periphery during diastole, thereby ensuring that the peripheral circulation receives a steady flow of blood during both cardiac cycles which are significantly different in terms of pressure. (b) Muscular arteries, especially those of the lower limb (eg femoral, popliteal, posterior tibial), which are capable of altering tone (the slightly contracted basal state of vascular smooth muscle) allowing them to modulate the velocity of the pressure wave that is conducted to them from the larger vessels upstream ${ }^{[10]}$. This modulation is also critical to normal function because of the concept of the "reflected wave". When the heart contracts, the resulting forward propagated wave interacts with the inherent impedance of the aorta that creates a relatively low velocity (pulse wave velocity; PWV) pressure wave ${ }^{[11]}$. As this wave propagates distally, it encounters regions of varying impedance mismatch arising from varying properties of the vascular wall and vascular diameter. These mismatches tend to amplify the forward propagated wave and also produce a partial wave reflection. Reflected waves from many points of impedance mismatch in the system summate to form an aggregate, backward (toward the heart) propagated wave that normally returns to the central aorta in late systole and early diastole. This returning "reflected" wave, by virtue of its timing in the cardiac cycle, offers a favorable diastolic pressure at the root of the aorta (near the openings of the coronary vasculature) that enhance coronary flow (Figure 1). 


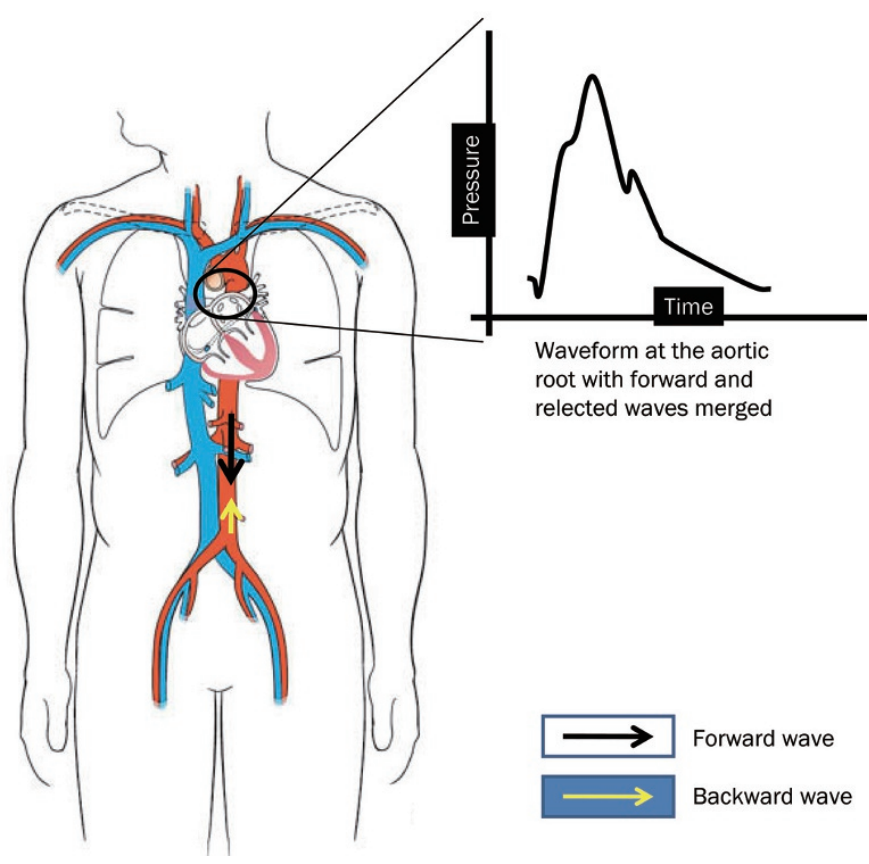

Figure 1. The aortic pressure waveform. Concept of the forward and backward propagated wave.

\section{Analysis of the aortic pressure waveform}

In a simplified and idealized model of the arterial system, a forward propagated pressure wave $\left(\mathrm{P}_{\mathrm{f}}\right)$ is created in the aorta following systole (Figure 2). This wave is propagated in the vessel lumen and as it travels distal to the heart, it encounters differences in the physical impedance offered by the vasculature (Figure 3). Such impedance "mismatches" occur when the aorta branches for example (such as the bronchial or esophageal arteries branching from the thoracic aorta, or the celiac or superior mesenteric arteries of the abdominal aorta), or further in the periphery where the relatively elastic nature of the aortic wall gives way to the thicker and more muscular vessels.

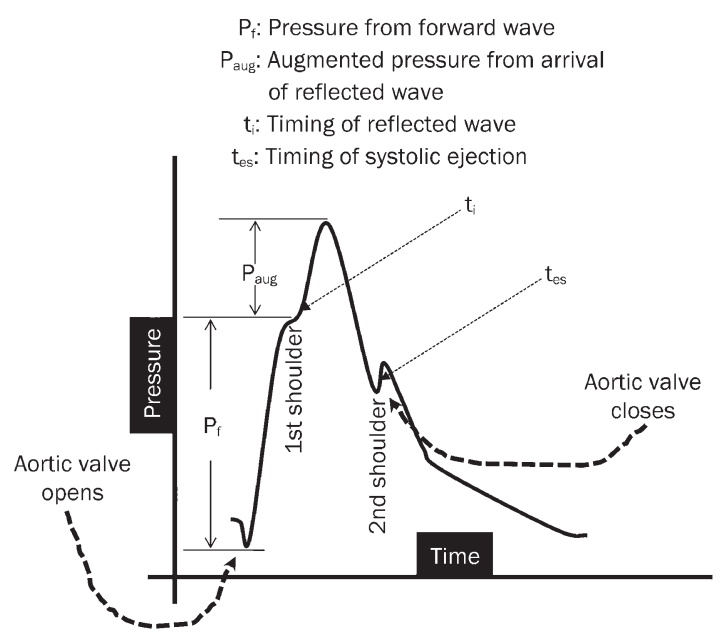

Figure 2. Aortic pressure waveform and its key components.

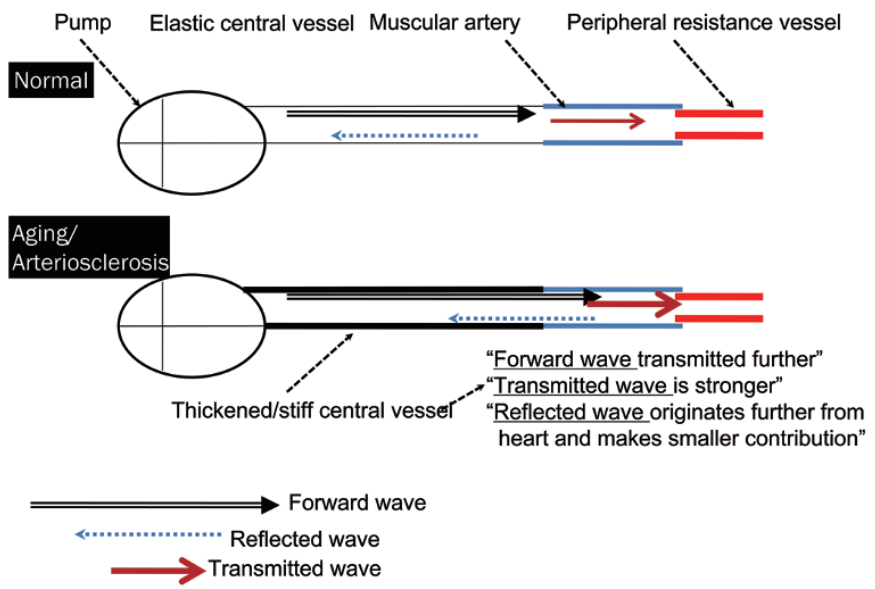

Figure 3. Effects of aging and stiffening of central elastic vessels, eg Aorta.

The aorta, pulmonary trunk and brachiocephalic trunk are examples of the large, elastic arteries of the arterial system. In these sizable vessels, there is a thick, highly developed media (tunica media) of which elastic fibers are the dominant component. Elastic fibers are gathered together in sheets arranged in concentric layers throughout the thickness of the media. In the aorta, these concentric elastic layers are arranged in as many as fifty distinct layers (Figure 4). The elastic nature of the aorta, for example, allows the vessel to distend to accommodate the considerable increase in blood volume when the heart goes into systole. In contrast, in a muscular artery (eg brachial, anterior tibial or coronary arteries) the elastic fibers are confined to two circumscribed rings: (a) the internal elastic lamina which is part of the tunica intima, and (b) the external elastic lamina of the tunica adventitia. The media of these intermediate sized vessels is relatively thick and is composed of smooth muscle fibers. It is the smooth muscle on the tunica media in these vessels that allows them to constrict or dilate, maintain tone and ultimately to closely regulate blood flow to

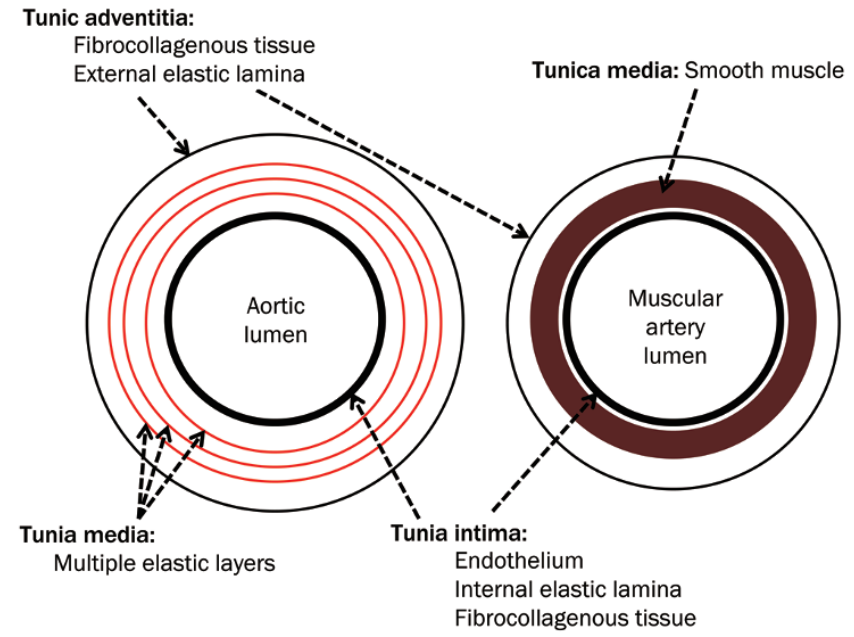

Figure 4. Comparative schemtatic: elastic artery vs muscular artery. 
their respective regions.

Upon cardiac systole, the forward propagated wave, $\mathrm{P}_{\mathrm{f}}$ travels down the aortic trunk and away from the central arterial axis as a distinct pressure wave. As described above, when this pressure wave encounters mismatched impedance, two components of the wave arise. The first is a transmitted pressure wave $\left(\mathrm{P}_{\mathrm{t}}\right)$ which is in the same direction as $\mathrm{P}_{\mathrm{f}}$ and it is this wave that continues further and deeper into the arterial system. A second, quantitatively smaller wave also arises and this is called the reflected pressure wave, or $P_{b}$ (Figure 3). This backward (ie against the direction of blood flow and toward the heart) wave arrives at the aortic root in late systole or early diastole, thus creating a secondary diastolic pressure in the aortic root that favors filling of the coronary vessels. This process is a physiologic mechanism that provides for robust coronary flow. This favorable rise in aortic pressure is called Pressure Augmentation ( $\mathrm{P}_{\text {aug }}$ in Figure 2). Normally, when the large elastic arteries (such as the aorta) are compliant (eg in a young adult), the forward propagated wave traveling from the heart is responsible for peak systolic blood pressure $(\mathrm{sBP})^{[10]}$. In this situation, the wave velocity is relatively slow (because physical waveforms travel with less efficiency in soft and compliant materials) and leads to a proportionately slow reflected wave that tends to arrive back from the periphery in diastole, thereby augmenting diastolic blood pressure (dBP) and preserving coronary perfusion ${ }^{[10]}$. Figure 2 represents a typical aortic pressure (pulse pressure; PP) waveform in a healthy adult. The PP wave has peculiar characteristics dependent on where it is measured. The aortic waveform, for example, is distinct from that measured in a peripheral muscular artery. The reason for this is partly due to the process described above and partly ascribed to the varying elastic qualities of the vasculature and the temporal and velocity differences in the reflected wave. In essence, the aortic PP is a composite wave which represents the change in pressure during one full cardiac cycle (starting from diastole, going through systole and returning to diastole) which shows the impact of both $P_{f}$ and $P_{b}$ on the pressure in the vessel (Figure 2). An analysis of the waveform reveals that as the aortic valve opens and blood flow into the proximal aorta increases exponentially following left ventricular contraction, the $\mathrm{P}_{\mathrm{f}}$ wave is initiated and begins propagation toward the periphery. At time $t_{i}$, the reflected wave $P_{b}$ arrives back at the aortic root and creates the first "shoulder" of the wave form. The reflected wave summates with the forward wave to establish a further increase in the PP and this is evidenced by the highest peak of the waveform beyond the first shoulder. In late systole when the blood flow at the aortic root has begun to diminish (by virtue of forward flow away from the heart), the PP starts to diminish precipitously until the PP reaches the second shoulder marked by closure of the aortic valve. The dynamics of valve closure creates perturbation of pressure reflected by the second shoulder following which the pressure quickly reaches diastolic levels ready to begin the next cycle again.

Because pressure augmentation is such a critically important element in aortic physiology and because it is closely pegged to the physical state of the arterial system, a mathematical derivation of this parameter is widely used in pulse wave analysis. This derivative is called Augmentation Index (AI) and it serves as an effective marker of aortic stiffness. The index is calculated as the increment in pressure from the first shoulder in the ascending trace of aortic waveform to the peak of the wave $(\Delta \mathrm{P})$, expressed as a percentage of the PP (Figure 5). The $\mathrm{AI}$ is directly dependent on three factors:

1. Cardiac cycle (or more specifically the heart rate).

2. The velocity of the pulse wave (PWV).

3. The amplitude of the reflected wave.

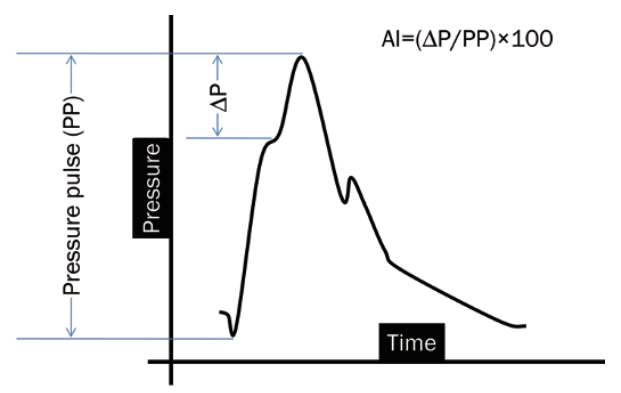

Figure 5. Derivation of Augmentation Index (Al).

Diastolic blood pressure and the sites from where the reflected wave originates (ie how far or how close to the heart; Figure 3), also influence AI, albeit more indirectly ${ }^{[12]}$. In healthy individuals who have compliant central arteries (owing to more pliable fibroelastic tissue in the media), AI is influenced more by the magnitude of the reflected wave rather than its velocity. This relationship is reversed in older individuals who have stiffer aortae ${ }^{[13]}$. Thus, an analysis of the pulse wave reveals important information about central systolic pressure, pulse pressure and central AI (AI at the aorta). However, pulse wave analysis is not considered a direct index of arterial stiffness and to achieve this, it has to be combined with measuring the PWV.

\section{Aortic waveform in the aged individual}

One of the sine qua nons of an aging vascular system is the presence of arteriosclerosis. In the specific context of the aorta, the vessel stiffens as well as dilates with age ${ }^{[14]}$. In addition, the thickness of the aortic wall increases even in the absence of atherosclerotic disease and is largely due to intimal thickening ${ }^{[15,16]}$. Vascular aging is strongly associated with elastin depletion and fragmentation, as well as collagen deposition $^{[17-19]}$. Cumulatively, these changes result in increased stiffness as well as increased augmentation of the central pressure $^{[18,20]}$. The clinical manifestation of such change is an increase in SBP and an increase in the pulse pressure ${ }^{[1,21]}$. Consequently, deleterious cardiovascular outcomes manifest with the greatest impact felt in the physiologic phenomenon called vascular-ventricular coupling (VVC). VVC is a complex property of the vascular system that allows the vascular load of the systemic and pulmonary system, via right and left 
ventricular outflows to the systemic arterial system in a manner that dampens the marked pulsatile nature of flow into a smooth pattern that places minimal dynamic loads on the progressively smaller vessels as blood is propagated through the system $^{[22]}$. Thus, altered VVC is also a critical manifestation of vascular stiffening and is another mechanistic element contributing to dysregulated blood flow that is observed in older individuals $^{[19]}$.

There is a marked difference in pressure augmentation between young and older individuals and this mainly arises from the phase difference of the effect of the reflected wave $(\mathrm{Pb})$ on central aortic pressure (as well as pressure measured in upper limb arteries) ${ }^{[23]}$ (Figure 6). Due to stiffening of the central elastic vessels (ie aorta), the reflected wave is conducted retrograde in the aorta with greater efficiency and tends to arrive in early systole in the ascending aorta (rather than late systole or early diastole in a younger subject). As a consequence, the summation between $\mathrm{Pf}$ and $\mathrm{Pb}$ is amplified (since it occurs on the ascending side of the pressure wave) (Figure 6). This amplification (more correctly called "augmentation") of pressure increases the peak of waveform in the systolic phase of the cardiac cycle while attenuating the physiologically favorable increase of diastolic pressure that would typically occur in a younger subject with more compliant central vessels (Figure 6).

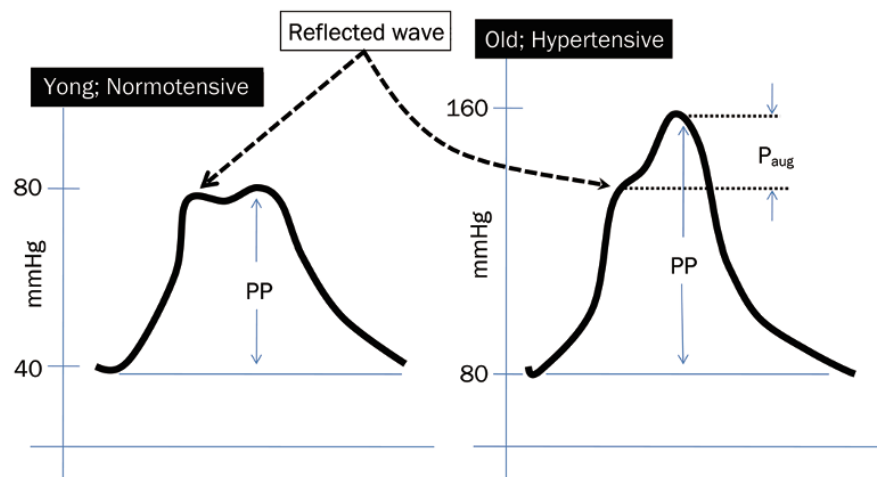

Figure 6. Aortic pressure waveform; young vs old (slightly exaggerated for clarity).

\section{Mechanisms of central arterial stiffening}

Generally, vascular stiffening occurs as a consequence of a complex interplay between a several independent as well as inter-dependent factors. Thus, the stiffening or hardening of the vessel wall associated with age is a macroscopic manifestation of hemodynamic forces ${ }^{[24]}$, the hormonal milieu, the intake of salt and the individual's glycemic state, as well as the global decline in cellular systems and function ${ }^{[5,25-27]}$.

Although stiffening of the central (or elastic) vasculature is a universal change associated with advancing age, it is also part of the phenotype in diseases such as hypertension and diabetes where complex cellular mechanisms conspire to accentuate hardening of the vessel wall.

\section{The role of collagen and elastin}

Vessel wall compliance is dependent on the status of two major scaffolding proteins: collagen and elastin ${ }^{[5]}$. Normally, there is a tightly regulated balance between synthesis and degradation of these two proteins. Anomalies occur in this regulatory system such as that which accrues from inflammatory change where collagen is over produced and elastin synthesis is undermined ${ }^{[28]}$. Such asymmetry contributes to arterial stiffening. In addition, increased luminal pressure (such as in hypertension) also tends to favor collagen production at the expense of elastin ${ }^{[29]}$. Indeed, histological examination of arterial tissue post-mortem appears to confirm that between the ages of 20 and 90 (the widest range of human longevity), there is doubling or tripling of the thickness of the tunica media ${ }^{[15,30]}$. When stiffened vessels are examined microscopically, a striking array of histological changes are observed. These include abnormal and disorganized endothelium, increased collagen, fragmented and diminished elastin, infiltration of smooth muscle cells, infiltration of macrophages, infiltration of mononuclear cells and increased matrix metalloprotease ${ }^{[5,31]}$. In addition, there is also an increase in transforming growth factor (TGF)- $\beta$, intercellular adhesion molecules (ICAM)s and cytokines in the vessel wall. Superimposed on thickening of the wall, there also appears to be a steady increase in vessel diameter with advancing age amounting to about $9 \%$ per decade from 20 to 60 years in the ascending aorta ${ }^{[32]}$.

\section{The role of matrix metalloproteases}

The extracellular matrix (ECM) of the vessel wall is made up of collagen, elastin, glycoproteins and proteoglycans ${ }^{[5]}$. Collagen and elastin (the proteins most closely linked to structural strength and elasticity) are themselves regulated by catabolic metalloproteases (MMPs). MMPs degrade the ECM by affecting the production of weaker collagen and frayed elastin fibers. When the vessel wall is exposed to immunological stress, inflammatory cells like polymorphonuclear neutrophils (PMNs) and macrophages, produce a variety of MMPs (MMP-1, -7, -8, -13) as well as elastase, and these enzymes are responsible for the deleterious changes described. The activity of these enzymes is regulated by augmented gene expression, post-translational activation of cleavage of pro-MMP, interaction between MMPs, plasmin, thrombin and reactive oxygen species $(\mathrm{ROS})^{[33-35]}$. On the other side of this equation, tissue inhibitors of MMPs (like TIMP1: tissue inhibitor of metalloproteases 1), counteract this process providing a regulatory mechanism to maintain a balance. Interestingly, other, perhaps less critical molecules, also participate in this dynamic scenario and these include chondroitin sulfate, heparan sulfate and fibronectin. Deposition of these molecules in the vessel wall also tends to thicken it and reduce its compliance ${ }^{[14]}$.

\section{Role of advanced glycation endproducts}

Advanced glycation endproducts (AGE) result from nonenzymatic protein glycation forming irreversible cross-links in stable tissue proteins like collagen ${ }^{[36,37]}$. When such crosslinking occurs, the resulting collagen is stiffer and resists 
regulatory turnover ${ }^{[36-38]}$. Similarly, elastin is also sensitive to AGE-associated cross-linking with the consequence that the contribution of this protein to the matrix in the vessel wall is steadily reduced from exposure to glycation ${ }^{[39,40]}$. AGE is also known to impact endothelial function by (a) quenching NO, and (b) enhancing the generation of reactive oxygen species (ROS), especially peroxynitrite ${ }^{[41]}$. Mounting evidence suggests that AGEs stimulate stress signaling and inflammatory responses such as boosting the expression of p12(ras), NF- $\mathrm{kB}$, ROS synthesis, generation of cytokines, growth factors and ICAMs and these, in turn, mediate vascular stiffness via MMP activity, endothelial dysfunction, increased smooth muscle tone (at least in muscular arteries), disturb the response of the endothelium to injury, affect angiogenesis and promote atherosclerosis $^{[42-47]}$.

\section{The role of endothelial dysfunction}

One of the typical clinical profiles associated with endothelial dysfunction is an impaired vasodilatory response to acetylcholine ${ }^{[48]}$. In part, this phenomenon is attributable to an imbalance between NO, endothelium-derived hyperpolarizing factor, vasoconstricting hormones and oxygenases (such as cyclooxygenase, NADPH and xanthine oxidase ${ }^{[5,49]}$. Studies have also shown (arriving at a somewhat subtly different conclusion) that instead of the cause and effect relationship between endothelial dysfunction and vascular stiffening, the opposite relationship may also hold true; ie vascular stiffening contributing to endothelial dysfunction. In this regard, a vicious cycle might exist where stiffening leads to endothelial disturbances and these in turn, worsen stiffening. For example, endothelial cells grown in distensible sialastic tubes exhibit stimulation of eNOS while those grown in rigid tubes, do not ${ }^{[50]}$. These and other studies have suggested that compliance of the vessel wall impacts endothelial mechanotransduction and that rigidity of the wall might promote a decline in NOS activity, promoting vascular stiffening ${ }^{[5]}$.

\section{The role of neuroendocrine signaling and diet}

Several hormones are thought to modulate vascular stiffness. For example, angiotensin II (AII) stimulates formation of collagen, triggers matrix remodeling and vascular hypertrophy, depresses NO-dependent signaling, increases ROS stress and reduces elastin synthesis ${ }^{[5,51]}$. Aldosterone also promotes stiffening in vessels and increases blood pressure by stimulating vascular smooth muscle cells (VSMC) hypertrophy, fibrosis and expression of fibronectin and also provokes hypertension via its function as a mineralocorticoid and through the stimulation of vasopressin release $\mathrm{e}^{[52,53]}$.

Dietary salt intake has also been shown to augment vascular stiffening, particularly with advancing age. Thus, low-sodium diets in older adults have been shown to improve vascular compliance $^{[54,55]}$. Mechanistically speaking, salt intake is associated with genetic modulation of angiotensin type 2 receptors, $\mathrm{NO}$ synthesis and synthesis of aldosterone ${ }^{[56-59]}$. $\mathrm{NaCl}$ can also impair endothelial function directly by interfering with eNOS activity and enhancing NADPH oxidase activity, pro- ducing the "double whammy" of aberrant NO signaling and oxidative stress in endothelial tissue and an overall effect of decreasing vascular compliance ${ }^{[54]}$.

\section{The role of glucose and insulin}

Amongst many other hallmarks of diabetic vasculopathology, arterial stiffening is arguably the most critical anomaly. In individuals who suffer from overt diabetes or metabolic syndrome, arterial stiffening is observed in all age groups. Children who are obese or have been diagnosed with metabolic syndrome, prematurely manifest signs of arterial stiffening ${ }^{[60]}$. It appears that insulin resistance is strongly positively correlated with stiffness of the vascular system and thus the association with obesity, anomalous insulin signaling and diabetes is not surprising. It has been shown, for example, that chronic hyperglycemia and hyperinsulinemia accentuate the activity of the renin-angiotensin-aldosterone axis as well as expression of angiotensin type 2 receptors in vascular tissue, leading to wall hypertrophy and fibrosis ${ }^{[61,62]}$. Impaired glucose tolerance is also known to enhance glycation of collagen thereby altering the vasoelastic properties of the vasculature. Stiffening is further exacerbated by LDL-induced endothelial dysfunction, insulin-induced anomalies in vascular tone and disordered biology of natriuretic peptides ${ }^{[63-65]}$.

\section{Role of genetics}

One of the most prominent epidemiological studies in cardiovascular medicine, the Farmingham Heart Study (FHS), has revealed some interesting insights into the genetic profile associated with vascular stiffening. In an analysis that used a genomic-scan approach among study participants, a 0.51-0.52 heritabililty estimate was reported for chronically increased arterial pulse pressure. This is a moderate association ${ }^{[66]}$. In addition, several highly suggestive regions contributing to high pulse pressure have been identified based in other cohorts and these include the $122 \mathrm{cM}$ region of chromosome 15 , the $164 \mathrm{cM}$ region of chromosome 8 and the $70 \mathrm{cM}$ region of chromosome $7^{[67-69]}$. Although candidate genes in these loci have not been identified in the context of causality of arterial stiffening, but their identity might ultimately reveal a genetic basis for elevated blood pressure and its structural link vascular stiffening. More direct associations have been discovered between human genotypes and arterial stiffening. For example, variations in arterial stiffness have been related to gene polymorphisms in the angiotensin converting enzyme (ACE) or angiotensin receptor, endothelin A and B receptor, collagen-Ia1, fibrillin-I, and insulin-like growth factor (IGF)-I ${ }^{[70-73]}$

\section{Clinical implications of arterial stiffening}

Decreased vascular compliance usually manifests in a clinical setting as isolated systolic hypertension (systolic blood pressure $>140 \mathrm{mmHg}$ and diastolic blood pressure $<90 \mathrm{mmHg}$ ). This is the inherent mathematical basis for an increased pulse pressure (PP), defined as the difference between systolic and diastolic blood pressure ${ }^{[8]}$. There is an interesting and per- 
vasive difference in the risk posed by high blood pressure in young versus older adults. Younger hypertensives experience high risk of cardiovascular morbidity from systolic, diastolic and mean arterial blood pressures (sBP, $\mathrm{dBP}$, and MAP). In contrast, cardiovascular, cerebrovascular and heart failure risk in older individuals is more closely linked to elevated PP and increased PWV (therefore increased stiffness, particularly of the aorta $)^{[3,74-78]}$. This difference implies that a different pathophysiologic mechanism underlies hypertension in young compared to old patients and that such a difference ought to be exploited in designing therapeutic strategies for these two cohorts.

Chronic elevation of MAP also leads to thickening of the vascular wall. Hypertension-induced remodeling is likely a compensatory mechanism prompted by vessel wall stress. In addition, changes in MAP tend to better correlate with changes in arterial compliance compared with systolic blood pressure $^{[5]}$. If one were to derive a distillate of these empirical studies and clinical trials, the basic dogma is reinforced that interventions to lower blood pressure that tend to ameliorate cardiovascular risk, do so by decreasing arterial stiffness (particularly as measured by assessment of PWV, AI and vascular compliance) ${ }^{[5]}$.

\section{Measuring aortic stiffness}

Obviously the aorta is not an ideally accessible vessel. Approaching the vessel surgically is neither desirable nor practical for the purpose of hemodynamic measurements. Thus, more indirect avenues and techniques have evolved to assess aortic stiffness in particular and arterial stiffness in general. Some of these techniques are useful to assess central arterial stiffness (ie aortic stiffness) while others, provide information on the compliance and stiffness of a peripheral vessel that is more accessible to measurement.

\section{Pulse pressure}

Pulse pressure (sBP-dBP) is a measure that is dependent on cardiac output, the stiffness of elastic central arteries like the aorta and wave reflection (above). Since the report by Bramwell and Hill, this parameter has acquired a central position as an effective and technically simple surrogate measure of aortic stiffness ${ }^{[79]}$. There is an interesting relationship between BP and age as graphically presented in Figure 7. Both sBP and $\mathrm{dBP}$ increase with advancing age. However, beyond 50-60 years, dBP increase tends to plateau and indeed decline with further increase in the individual's age. Thus, while initially the pulse pressure tends not to change very much, in later life it begins to increase precipitously ${ }^{[1,80]}$. The great advantage of PP is that it can be determined simply by clinical, or even home-based BP measurement, typically with a sphygmomanometer. Certain caveats have to be borne in mind while using PP as a measure of aortic stiffness. First, at least two other elements contribute to PP (above). Second, the physiological amplification (not to be confused with "augmentation") that occurs as the arterial pressure wave propagates peripherally, tends to confound PP

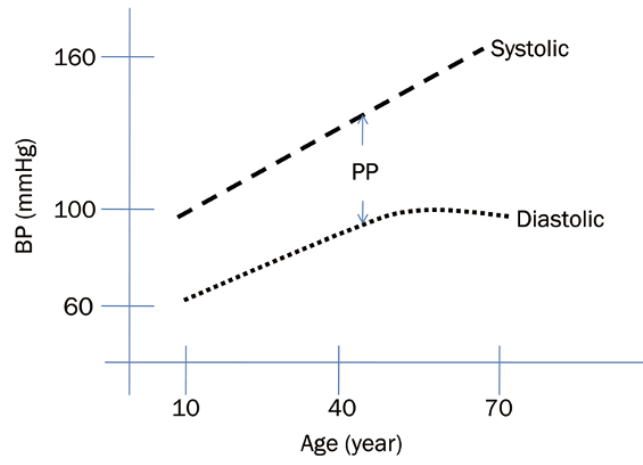

Figure 7. Effect of age on systolic, diastolic and pulse pressure.

as a measure of central stiffness. However, the amplification becomes less pronounced in older subjects and this somewhat redeems the limitation of PP measurement in the elderly. The discrepancy between peripherally measured BP and central arterial pressure can be as significant as $20 \mathrm{mmHg}$ in different individuals who have similar (within the margin of error) recording made from the brachial artery (the standard site for clinical BP assessment) ${ }^{[81]}$.

\section{Pulse wave velocity (PWV)}

While PWV is an easy enough concept to understand, it is a frustratingly difficult measure to obtain. It is quite simply, the velocity of the forward propagated arterial pressure wave $\left(P_{f}\right.$ in the discussion above). To measure this velocity accurately, in the absence of access of the aortic axis, the time taken by the arterial waveform between two points that are a measured distance apart is determined. Practically, this can be done either by taking two recording from the two sites simultaneously, or gating the recording to a fixed point in the cardiac cycle (such as the R wave of the QRS complex on an EKG trace). The inherent limitation of PWV measurements (other than the inability to record from the aorta itself) is that the velocity measure becomes less accurate if the distance between the two sites is small. Given the nature of surface vascular anatomy, obtaining a large enough distance between the two points of measurement, can quickly become untenable. Mathematically, PWV is dependent on vessel distensibility which is inversely related to stiffness. More formally, the Moens-Korteweg equation describes this relationship thus:

$$
P W V=\sqrt{ }(\text { Eh } / 2 r \rho)
$$

Here, E is the Young's modulus of elasticity (a measure of stiffness of an elastic material and technically the ratio between stress and strain), $h$ is the thickness of the vessel wall, $r$ is the internal radius of the vessel and $\rho$ is density of blood. Bramwell and Hill further derived this equation to give:

$$
\mathrm{PWV}=\sqrt{ }(\Delta \mathrm{PV} / \Delta \mathrm{V} \rho)
$$

Or

$$
P W V=\sqrt{ }(1 / \rho D)
$$

Here, $\Delta \mathrm{P}$ is the change in arterial pressure, $\Delta \mathrm{V}$ is the change in arterial volume and $\mathrm{D}$ is distensibility. Distensibility is related to pressure and volume in this manner: 


$$
\mathrm{D}=\Delta \mathrm{V} /(\Delta \mathrm{P} \cdot \mathrm{V})
$$

In addition, compliance of the vessel is given by:

$$
\text { Compliance }=\Delta \mathrm{V} / \Delta \mathrm{P}
$$

In a practical sense, $\mathrm{PWV}$ is measured by obtaining a recording of the arterial pulse wave at a proximal artery such as the common carotid, as well as a distal vessel such as the femoral. These two vessels are widely used because they are relatively superficial permitting accurate identification and ease in using a tonometer. An added advantage is that the distance between these two sites is comparable to aortic length, thereby exploiting the distance as a simulation of aortic measurement. The time delay between the pulse between these two points is usually gate to the R'wave. The instrument used for this purpose is called a pulse tonometer and several companies provide apparatuses that combine the probe, computer and analysis software in one unit (Figure 8).

Using ultrasonic technology to measure arterial stiffness: Ultrasonic apparatus (as used in clinical applications) can be used with relative accuracy to derive distensibility and compliance of the vessel. Ultrasonic imaging is best used for larger vessels that are not surrounded by dense bone or tissue. Thus the brachial, femoral and carotid vessels are good candidates and the abdominal aorta is somewhat intermediate in term of image quality obtainable. Several images of the selected vessel are obtained per cardiac cycle and the change in volume is calculated by tracking the movement of the vessel wall with the assistance of computer software. As discussed above, distensibility and compliance can be measured using mathematical algorithms. A significant disadvantage of this technique is that the equipment tends to be expensive and operator training is mandatory to obtain reliable and reproducible information $^{[80]}$. Operator bias has recently been improved by using robotic placement of the ultrasonic probe but this strategy amplifies the price of the equipment exponentially. Another, more technical limitation of this method of measuring aortic compliance is that blood pressure has to be measured and the only avenue is to measure it at the periphery. As discussed above, this is a very approximate measure of central pressure and therefore introduces an additional confounding inaccuracy to the technique.

\section{MRI derived measurement of arterial stiffness: Magnetic resonance}

Imaging (MRI) is now a widespread imaging tool in the clinical world and is also becoming accessible in the medical research setting. Typically, MRI based analyses of stiffness involve a quantification of aortic distension and its relationship to compliance. MRI has the advantage of being non-invasive but is hampered by expense and availability. However, it is a relatively accurate and objective measure and is an important option both clinically and for research in both human and animal subjects ${ }^{[80]}$.

\section{Waveform analysis}

The arterial pressure waveform was first recorded over a hundred years ago using the sphygmograph. In the interim, modifications of the same principle have been employed with considerable success to measure arterial stiffness and the most recent innovation is applanation tonometry (AP). AP involves using a tonometer probe to record a pressure waveform from a surface artery (like the radial or carotid) after it has been gently compressed against an underlying bony landmark. Such compression allows an equalization of circumferential pressures and enables a high fidelity waveform to be recorded. O'Rourke and Gallagher have published a simple and validated method of using AP to quantify stiffness ( $\mathrm{O}^{\prime}$ Rourke Pulse Wave analysis; PWA) in which the AI can be derived and central arterial pressure can be estimated ${ }^{[82]}$. Less widely used methods are also available that rely on waveform analysis and include pressure pulse contour analysis, plethysmography and oscillometric blood pressure measurement ${ }^{[80,83,84]}$.

\section{Measuring arterial stiffening in research animals}

Vascular biology has been revolutionized by the genetic
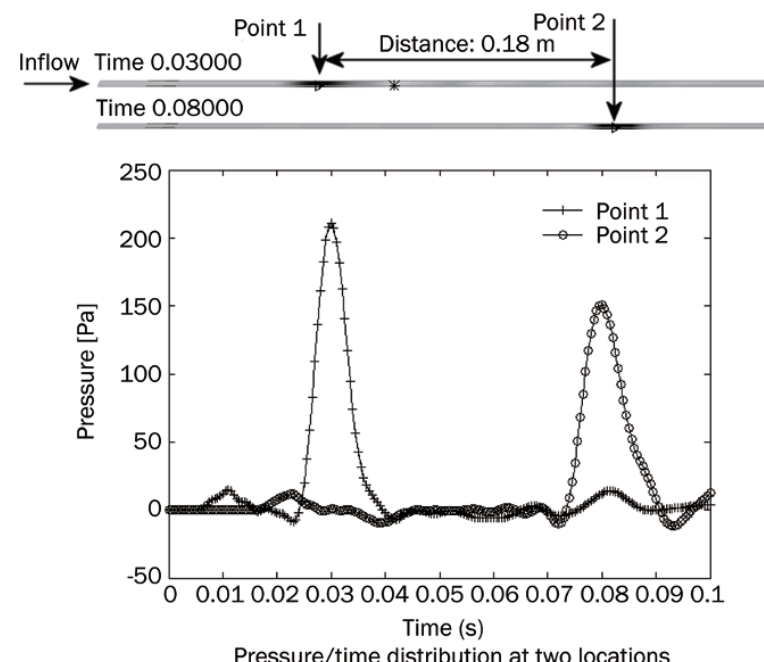

NODAL PRESSURE Time $0.0300(\mathrm{kPa})$ 0.1400 0.1400
0.1000 0.1000
0.0800 0.0600 0.0400 0.0000 -0.0200
-0.0400 $-0.0400$

Estimation of the PWV by the time delay of the pressure wave at two characteristic points: $\mathrm{c}=3,6 \mathrm{~m} / \mathrm{s}$

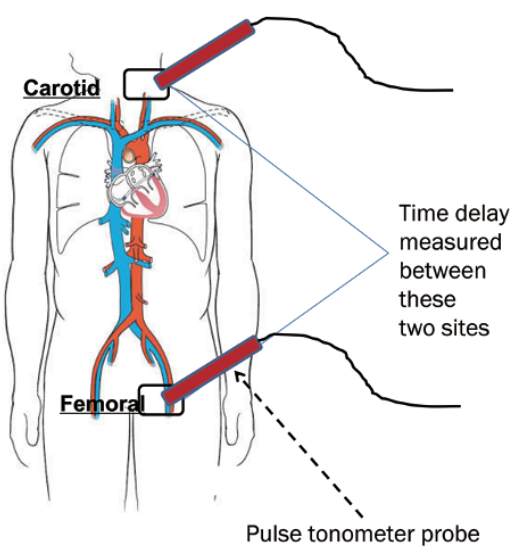

Figure 8. Measuring the pulse wave velocity (PWV). 
manipulation of research animals with the advent of genetic knockout and gene silencing techniques. Thus, almost every vascular pathology observed in humans has a counterpart animal model and in most cases a variety of models are used to study individual vasculopathies. The techniques described above, generally are uniformly applicable for use in laboratory animals ranging from rodents to primates and have been used with fair success. The limitations of such research are attributable to expertise, expense and availability. However, as our understanding of the mechanistic determinant of vascular stiffness and compliance is enhanced, it can be predicted that these techniques will come into increasing use both clinically as well as empirically. Indeed advances in non-invasive biotechnology would also likely enhance their accuracy and easeof-use concomitant with decreasing associated expense.

\section{Conclusions}

We are over a century on in recognizing the predictive value of arterial stiffness in cardiovascular disease. Recent evidence also suggests that this property of the vascular system may harbor diagnostic insights in cardiovascular and metabolic diseases as well. Methods of measuring stiffness and compliance in blood vessels have been refined to the point that these measurements have become entirely non-invasive, increasingly specific, remarkably sensitive and consistently reproducible and verifiable. Several important epidemiological studies in the Western hemisphere have involved arterial stiffness measures in their analyses. These include the ASCOT study in hypertension, the SEARCH study of hypercholesterolemia and the FIELD trial in type 2 diabetes, among others (for detailed analyses of the results of these studies relevant to arterial stiffness, URL references can be searched ${ }^{[85-87]}$ ). The results of these studies should help to clarify the role of arterial stiffness in human pathology. Overall, there appears to by accumulating consensus that promoting research in arterial stiffness in several areas of clinical and research relevance will likely yield exciting insights. These could include assessing the efficacy of different classes of hypertensive medications, particularly those used for isolated systolic hypertension as prominent examples ${ }^{[80]}$. Future investigations to study arterial stiffness may shed light on the potential to use this parameter of vascular biology as a diagnostic and therapeutic target with broad impact on diseases ranging from cardiovascular disorders through stroke to hypertension and diabetes.

\section{Acknowledgements}

This work discussed in manuscript was supported in part by NIH grants (HL079584, HL074399, HL080499, HL089920, and HL096032), and by research awards from the American Diabetes Association, Juvenile Diabetes Research Foundation, Oklahoma Center for Advancement of Science and Technology, and a Travis Endowed Chair in Endocrinology, University of Oklahoma Health Sciences Center. Dr Ming-hui ZOU is a recipient of a National Established Investigator Award from the American Heart Association.

\section{References}

1 Franklin SS, Gustin Wt, Wong ND, Larson MG, Weber MA, Kannel WB, et al. Hemodynamic patterns of age-related changes in blood pressure. The Framingham Heart Study. Circulation 1997; 96: 30815.

2 Sutton-Tyrrell K, Najjar SS, Boudreau RM, Venkitachalam L, Kupelian $\mathrm{V}$, Simonsick EM, et al. Elevated aortic pulse wave velocity, a marker of arterial stiffness, predicts cardiovascular events in well-functioning older adults. Circulation 2005; 111: 3384-90.

3 Chae CU, Pfeffer MA, Glynn RJ, Mitchell GF, Taylor JO, Hennekens CH. Increased pulse pressure and risk of heart failure in the elderly. JAMA 1999; 281: 634-9.

4 Mitchell GF, Vasan RS, Keyes MJ, Parise H, Wang TJ, Larson MG, et al. Pulse pressure and risk of new-onset atrial fibrillation. JAMA 2007; 297: 709-15.

5 Zieman SJ, Melenovsky V, Kass DA. Mechanisms, pathophysiology, and therapy of arterial stiffness. Arterioscler Thromb Vasc Biol 2005; 25: 932-43.

6 Collins AJ, Li S, Gilbertson DT, Liu J, Chen SC, Herzog CA. Chronic kidney disease and cardiovascular disease in the medicare population. Kidney Int Suppl 2003; (87): S24-31.

7 Scuteri A, Najjar SS, Muller DC, Andres R, Hougaku H, Metter EJ, et al. Metabolic syndrome amplifies the age-associated increases in vascular thickness and stiffness. J Am Coll Cardiol 2004; 43: 138895.

8 Dart AM, Kingwell BA. Pulse pressure - a review of mechanisms and clinical relevance. J Am Coll Cardiol 2001; 37: 975-84.

9 Lakatta EG, Levy D. Arterial and cardiac aging: major shareholders in cardiovascular disease enterprises: Part II: the aging heart in health: links to heart disease. Circulation 2003; 107: 346-54.

10 Gkaliagkousi E, Douma S. The pathogenesis of arterial stiffness and its prognostic value in essential hypertension and cardiovascular diseases. Hippokratia 2009; 13: 70-5.

11 Mitchell GF. Effects of central arterial aging on the structure and function of the peripheral vasculature: implications for end-organ damage. J Appl Physiol 2008; 105: 1652-60.

12 Laurent S, Cockcroft J, Van Bortel L, Boutouyrie P, Giannattasio C, Hayoz D, et al. Expert consensus document on arterial stiffness: methodological issues and clinical applications. Eur Heart J 2006; 27: 2588-605.

13 Kelly RP, Millasseau SC, Ritter JM, Chowienczyk PJ. Vasoactive drugs influence aortic augmentation index independently of pulse-wave velocity in healthy men. Hypertension 2001; 37: 1429-33.

14 Lakatta EG. Cardiovascular regulatory mechanisms in advanced age. Physiol Rev 1993; 73: 413-67.

15 Nagai Y, Metter EJ, Fleg JL. Increased carotid artery intimal-medial thickness: risk factor for exercise-induced myocardial ischemia in asymptomatic older individuals. Vasc Med 1999; 4: 181-6.

16 Virmani R, Avolio AP, Mergner WJ, Robinowitz M, Herderick EE, Cornhill $\mathrm{JF}$, et al. Effect of aging on aortic morphology in populations with high and low prevalence of hypertension and atherosclerosis. Comparison between occidental and Chinese communities. Am J Pathol 1991; 139: 1119-29.

17 O'Rourke MF, Nichols WW. Aortic diameter, aortic stiffness, and wave reflection increase with age and isolated systolic hypertension. Hypertension 2005; 45: 652-8.

18 Kass DA. Age-related changes in venticular-arterial coupling: pathophysiologic implications. Heart Fail Rev 2002; 7: 51-62.

19 Santhanam L, Christianson DW, Nyhan D, Berkowitz DE. Arginase and vascular aging. J Appl Physiol 2008; 105: 1632-42.

20 Nichols WW. Clinical measurement of arterial stiffness obtained from 
noninvasive pressure waveforms. Am J Hypertens 2005; 18 (1 Pt 2): 3S-10S.

21 Wilkinson IB, Franklin SS, Hall IR, Tyrrell S, Cockcroft JR. Pressure amplification explains why pulse pressure is unrelated to risk in young subjects. Hypertension 2001; 38: 1461-6.

22 O'Rourke MF, Yaginuma T, Avolio AP. Physiological and pathophysiological implications of ventricular/vascular coupling. Ann Biomed Eng 1984; 12: 119-34.

23 Hirata K, Kawakami M, O'Rourke MF. Pulse wave analysis and pulse wave velocity: a review of blood pressure interpretation 100 years after Korotkov. Circ J 2006; 70: 1231-9.

24 Wolinsky H, Glagov S. Structural basis for the static mechanical properties of the aortic media. Circ Res 1964; 14: 400-13.

25 Galis ZS, Khatri JJ. Matrix metalloproteinases in vascular remodeling and atherogenesis: the good, the bad, and the ugly. Circ Res 2002; 90: 251-62.

26 Beattie D, Xu C, Vito R, Glagov S, Whang MC. Mechanical analysis of heterogeneous, atherosclerotic human aorta. J Biomech Eng 1998; 120: 602-7.

27 Bassiouny HS, Zarins CK, Kadowaki MH, Glagov S. Hemodynamic stress and experimental aortoiliac atherosclerosis. J Vasc Surg 1994; 19: 426-34.

28 Johnson CP, Baugh R, Wilson CA, Burns J. Age related changes in the tunica media of the vertebral artery: implications for the assessment of vessels injured by trauma. J Clin Pathol 2001; 54: 139-45.

29 Xu C, Zarins CK, Pannaraj PS, Bassiouny HS, Glagov S. Hypercholesterolemia superimposed by experimental hypertension induces differential distribution of collagen and elastin. Arterioscler Thromb Vasc Biol 2000; 20: 2566-72.

30 O'Leary DH, Polak JF, Kronmal RA, Manolio TA, Burke GL, Wolfson SK Jr. Carotid-artery intima and media thickness as a risk factor for myocardial infarction and stroke in older adults. Cardiovascular Health Study Collaborative Research Group. N Engl J Med 1999; 340: 14-22.

31 Lakatta EG. Arterial and cardiac aging: major shareholders in cardiovascular disease enterprises: Part III: cellular and molecular clues to heart and arterial aging. Circulation 2003; 107: 490-7.

32 Watanabe M, Sawai T, Nagura H, Suyama K. Age-related alteration of cross-linking amino acids of elastin in human aorta. Tohoku J Exp Med 1996; 180: 115-30.

33 Visse R, Nagase $\mathrm{H}$. Matrix metalloproteinases and tissue inhibitors of metalloproteinases: structure, function, and biochemistry. Circ Res 2003; 92: 827-39.

34 Dollery CM, McEwan JR, Henney AM. Matrix metalloproteinases and cardiovascular disease. Circ Res 1995; 77: 863-8.

35 Rajagopalan S, Meng XP, Ramasamy S, Harrison DG, Galis ZS. Reactive oxygen species produced by macrophage-derived foam cells regulate the activity of vascular matrix metalloproteinases in vitro. Implications for atherosclerotic plaque stability. J Clin Invest 1996; 98: 2572-9.

36 Lee AT, Cerami A. Role of glycation in aging. Ann N Y Acad Sci 1992; 663: 63-70.

37 Bailey AJ. Molecular mechanisms of ageing in connective tissues. Mech Ageing Dev 2001; 122: 735-55.

38 Verzijl N, DeGroot J, Thorpe SR, Bank RA, Shaw JN, Lyons TJ, et al. Effect of collagen turnover on the accumulation of advanced glycation end products. J Biol Chem 2000; 275: 39027-31.

39 Winlove CP, Parker KH, Avery NC, Bailey AJ. Interactions of elastin and aorta with sugars in vitro and their effects on biochemical and physical properties. Diabetologia 1996; 39: 1131-9.

40 Konova E, Baydanoff S, Atanasova M, Velkova A. Age-related changes in the glycation of human aortic elastin. Exp Gerontol 2004; 39: 249-54.

41 Rojas A, Romay S, Gonzalez D, Herrera B, Delgado R, Otero K. Regulation of endothelial nitric oxide synthase expression by albumin-derived advanced glycosylation end products. Circ Res 2000; 86: E50-4.

42 Yan SD, Schmidt AM, Anderson GM, Zhang J, Brett J, Zou YS, et al. Enhanced cellular oxidant stress by the interaction of advanced glycation end products with their receptors/binding proteins. J Biol Chem 1994; 269: 9889-97.

43 Throckmorton DC, Brogden AP, Min B, Rasmussen H, Kashgarian M. PDGF and TGF-beta mediate collagen production by mesangial cells exposed to advanced glycosylation end products. Kidney Int 1995; 48: 111-7.

44 Kuzuya M, Asai T, Kanda S, Maeda K, Cheng XW, Iguchi A. Glycation cross-links inhibit matrix metalloproteinase-2 activation in vascular smooth muscle cells cultured on collagen lattice. Diabetologia 2001; 44: 433-6.

45 Wendt T, Bucciarelli L, Qu W, Lu Y, Yan SF, Stern DM, et al. Receptor for advanced glycation endproducts (RAGE) and vascular inflammation: insights into the pathogenesis of macrovascular complications in diabetes. Curr Atheroscler Rep 2002; 4: 228-37.

46 Stern DM, Yan SD, Yan SF, Schmidt AM. Receptor for advanced glycation endproducts (RAGE) and the complications of diabetes. Ageing Res Rev 2002; 1: 1-15.

47 Schmidt AM, Stern D. Atherosclerosis and diabetes: the RAGE connection. Curr Atheroscler Rep 2000; 2: 430-6.

48 Taddei S, Virdis A, Mattei P, Ghiadoni L, Gennari A, Fasolo CB, et al. Aging and endothelial function in normotensive subjects and patients with essential hypertension. Circulation 1995; 91: 1981-7.

49 Matz RL, Schott C, Stoclet JC, Andriantsitohaina R. Age-related endothelial dysfunction with respect to nitric oxide, endotheliumderived hyperpolarizing factor and cyclooxygenase products. Physiol Res 2000; 49: 11-8.

50 Peng X, Haldar S, Deshpande S, Irani K, Kass DA. Wall stiffness suppresses Akt/eNOS and cytoprotection in pulse-perfused endothelium. Hypertension 2003; 41: 378-81.

51 Dzau VJ. Significance of the vascular renin-angiotensin pathway. Hypertension 1986; 8: 553-9.

52 Lacolley P, Labat C, Pujol A, Delcayre C, Benetos A, Safar M. Increased carotid wall elastic modulus and fibronectin in aldosteronesalt-treated rats: effects of eplerenone. Circulation 2002; 106: 2848-53.

53 Blacher J, Amah G, Girerd X, Kheder A, Ben Mais H, London GM, et al. Association between increased plasma levels of aldosterone and decreased systemic arterial compliance in subjects with essential hypertension. Am J Hypertens 1997; 10: 1326-34.

54 Bagrov AY, Lakatta EG. The dietary sodium-blood pressure plot "stiffens". Hypertension 2004; 44: 22-4.

55 Gu JW, Anand V, Shek EW, Moore MC, Brady AL, Kelly WC, et al. Sodium induces hypertrophy of cultured myocardial myoblasts and vascular smooth muscle cells. Hypertension 1998; 31: 1083-7.

56 Pojoga L, Gautier S, Blanc H, Guyene TT, Poirier O, Cambien F, et al. Genetic determination of plasma aldosterone levels in essential hypertension. Am J Hypertens 1998; 11: 856-60.

57 Benetos A, Cambien F, Gautier S, Ricard S, Safar M, Laurent S, et al. Influence of the angiotensin II type 1 receptor gene polymorphism on the effects of perindopril and nitrendipine on arterial stiffness in hypertensive individuals. Hypertension 1996; 28: 1081-4.

58 Benetos A, Gautier S, Ricard S, Topouchian J, Asmar R, Poirier O, et al. Influence of angiotensin-converting enzyme and angiotensin II type 1 receptor gene polymorphisms on aortic stiffness in normotensive and 
hypertensive patients. Circulation 1996; 94: 698-703.

59 Lacolley P, Gautier S, Poirier O, Pannier B, Cambien F, Benetos A. Nitric oxide synthase gene polymorphisms, blood pressure and aortic stiffness in normotensive and hypertensive subjects. J Hypertens 1998; 16: 31-5.

60 Tounian P, Aggoun Y, Dubern B, Varille V, Guy-Grand B, Sidi D, et al. Presence of increased stiffness of the common carotid artery and endothelial dysfunction in severely obese children: a prospective study. Lancet 2001; 358: 1400-4.

61 Jesmin S, Sakuma I, Hattori Y, Kitabatake A. Role of angiotensin II in altered expression of molecules responsible for coronary matrix remodeling in insulin-resistant diabetic rats. Arterioscler Thromb Vasc Biol 2003; 23: 2021-6.

62 Nickenig G, Roling J, Strehlow K, Schnabel P, Bohm M. Insulin induces upregulation of vascular AT1 receptor gene expression by posttranscriptional mechanisms. Circulation 1998; 98: 2453-60.

63 Steinberg HO, Tarshoby M, Monestel R, Hook G, Cronin J, Johnson A, et al. Elevated circulating free fatty acid levels impair endotheliumdependent vasodilation. J Clin Invest 1997; 100: 1230-9.

64 Matsuzawa Y, Funahashi T, Kihara S, Shimomura I. Adiponectin and metabolic syndrome. Arterioscler Thromb Vasc Biol 2004; 24: 29-33.

65 Wang TJ, Larson MG, Levy D, Benjamin EJ, Leip EP, Wilson PW, et al. Impact of obesity on plasma natriuretic peptide levels. Circulation 2004; 109: 594-600.

66 Levy D, DeStefano AL, Larson MG, O’Donnell CJ, Lifton RP, Gavras H, et al. Evidence for a gene influencing blood pressure on chromosome 17. Genome scan linkage results for longitudinal blood pressure phenotypes in subjects from the framingham heart study. Hypertension 2000; 36: 477-83.

67 Xu X, Yang J, Rogus J, Chen C, Schork N. Mapping of a blood pressure quantitative trait locus to chromosome $15 q$ in a Chinese population. Hum Mol Genet 1999; 8: 2551-5.

68 Atwood LD, Samollow PB, Hixson JE, Stern MP, MacCluer JW. Genomewide linkage analysis of blood pressure in Mexican Americans. Genet Epidemiol 2001; 20: 373-82.

69 Camp NJ, Hopkins PN, Hasstedt SJ, Coon H, Malhotra A, Cawthon RM, et al. Genome-wide multipoint parametric linkage analysis of pulse pressure in large, extended Utah pedigrees. Hypertension 2003; 42: 322-8.

70 Cambien F, Costerousse O, Tiret L, Poirier O, Lecerf L, Gonzales MF, et al. Plasma level and gene polymorphism of angiotensin-converting enzyme in relation to myocardial infarction. Circulation 1994; 90: 669-76.

71 Lajemi M, Gautier S, Poirier O, Baguet JP, Mimran A, Gosse P, et al. Endothelin gene variants and aortic and cardiac structure in nevertreated hypertensives. Am J Hypertens 2001; 14: 755-60.

72 Brull DJ, Murray LJ, Boreham CA, Ralston SH, Montgomery HE, Gallagher AM, et al. Effect of a COL1A1 Sp1 binding site polymorphism on arterial pulse wave velocity: an index of compliance. Hyper- tension 2001; 38: 444-8.

73 Schut AF, Janssen JA, Deinum J, Vergeer JM, Hofman A, Lamberts SW, et al. Polymorphism in the promoter region of the insulin-like growth factor I gene is related to carotid intima-media thickness and aortic pulse wave velocity in subjects with hypertension. Stroke 2003; 34: 1623-7.

74 Mitchell GF, Moye LA, Braunwald E, Rouleau JL, Bernstein V, Geltman $\mathrm{EM}$, et al. Sphygmomanometrically determined pulse pressure is a powerful independent predictor of recurrent events after myocardial infarction in patients with impaired left ventricular function. SAVE investigators. Survival and ventricular enlargement. Circulation 1997; 96: 4254-60.

75 Vaccarino V, Berger AK, Abramson J, Black HR, Setaro JF, Davey JA, et al. Pulse pressure and risk of cardiovascular events in the systolic hypertension in the elderly program. Am J Cardiol 2001; 88: 980-6.

76 Kostis JB, Lawrence-Nelson J, Ranjan R, Wilson AC, Kostis WJ, Lacy $\mathrm{CR}$. Association of increased pulse pressure with the development of heart failure in SHEP. Systolic Hypertension in the Elderly (SHEP) Cooperative Research Group. Am J Hypertens 2001; 14: 798-803.

77 Franklin SS, Khan SA, Wong ND, Larson MG, Levy D. Is pulse pressure useful in predicting risk for coronary heart disease? The Framingham heart study. Circulation 1999; 100: 354-60.

78 O'Donnell CJ, Ridker PM, Glynn RJ, Berger K, Ajani U, Manson JE, et al. Hypertension and borderline isolated systolic hypertension increase risks of cardiovascular disease and mortality in male physicians. Circulation 1997; 95: 1132-7.

79 Bramwell JC, Hill AV. Velocity of transmission of the pulse-wave and elasticity of the arteries. Lancet 1922; i: 891-2.

80 Mackenzie IS, Wilkinson IB, Cockcroft JR. Assessment of arterial stiffness in clinical practice. QJM 2002; 95: 67-74.

81 Wilkinson IB, MacCallum H, Flint L, Cockcroft JR, Newby DE, Webb DJ. The influence of heart rate on augmentation index and central arterial pressure in humans. J Physiol 2000; 525: 263-70.

82 O'Rourke MF, Gallagher DE. Pulse wave analysis. J Hypertens Suppl 1996; 14: S147-57.

83 Cohn JN, Finkelstein S, McVeigh G, Morgan D, LeMay L, Robinson J, et al. Noninvasive pulse wave analysis for the early detection of vascular disease. Hypertension 1995; 26: 503-8.

84 Chowienczyk PJ, Kelly RP, MacCallum H, Millasseau SC, Andersson TL, Gosling RG, et al. Photoplethysmographic assessment of pulse wave reflection: blunted response to endothelium-dependent beta2adrenergic vasodilation in type II diabetes mellitus. J Am Coll Cardiol 1999; 34: 2007-14.

85 SEARCh for Diabetes in Youth [Available from: http://www.searchfordiabetes.org

86 Fenofibrate Intervention and Event Lowering in Diabetes [Available from: http://www.fieldstudy.info/investigators/index.asp

87 Anglo-Scandinavian Cardiac Outcomes Trial [Available from: http:// www.ascotstudy.org/home.htm 